\title{
APROPRIAÇÃO DO CERRADO POR UNIDADES DE CONSERVAÇÃO E A EDUCAÇÃO AMBIENTAL
}

Appropriation of the Cerrado by Conservation Units and Environmental

Education

Gabriela Couto Barbosa

http://dx.doi.org/10.21116/2019.8

Universidade Estadual de Campinas

Cláudia Valéria de Lima

Universidade Federal de Goiás

\section{André Munhoz de Argollo Ferrão}

Universidade Estadual de Campinas

\section{João Vitor Silva}

Universidade Federal de Goiás

Resumo: O presente trabalho tem como objetivo discutir a presença de unidades de conservação em Goiás e no Distrito Federal como ferramenta para atividades no âmbito da educação ambiental no Cerrado, com ênfase nas unidades de conservação do tipo parque nacional. Sabe-se que a apropriação do Cerrado acontece há tempos e por diferentes atores. Parte significante dessa apropriação é realizada por atores que degradam o ambiente do Cerrado, como a agropecuária. Este trabalho visa analisar a prática da educação ambiental em unidades de conservação e a importância para a conservação do Cerrado. Foi realizada uma fundamentação teórica acerca do conceito de Cerrado e suas características, assim como uma discussão sobre unidades de conservação e educação ambiental. Além disso, há uma breve análise histórica, social e física das características das unidades de conservação selecionadas e do Cerrado.

Palavras-chave: unidade de conservação; Cerrado; educação ambiental.

Summary: This paper aims to discuss the creation of conservation units in Goiás and the Federal District as a tool for activities in the field of Environmental Education in the Cerrado, with emphasis on national park type conservation units. It is known that the appropriation of the Cerrado has been happening for a long time and by different actors. A significant part of this appropriation is performed by actors that degrade the Cerrado environment, such as agriculture. This paper aims to analise the practice of environmental education in conservations units and the importance to Cerrado's conservation. A theoretical basis was made about the concept of Cerrado and its characteristics, as well as a discussion about conservation units and environmental education. In addition, there is a brief historical, social and physical analysis of the characteristics of selected protected areas and the Cerrado.

Keywords: conservation unit, Cerrado, environmental education. 


\section{INTRODUÇÃO}

O Cerrado presente no estado de Goiás e no Distrito Federal sofreu diferentes tipos de apropriações de acordo com as diversas atividades desenvolvidas. Algumas destas apropriações causaram e causam a diminuição da área do Cerrado, como é o caso do agronegócio. No entanto, outras atividades possuem o objetivo de preservação e conservação de tal bioma, como é o caso das Unidades de Conservação (UC).

O presente trabalho tem como objetivo principal discutir a presença de Unidades de Conservação como ferramentas para a Educação Ambiental a partir da apropriação do Cerrado no estado de Goiás e no Distrito Federal. Como objetivos específicos tem-se uma breve revisão sobre o Cerrado, análise da situação das Unidades de Conservação no Brasil, no estado de Goiás e no Distrito Federal e das UC's selecionadas, além de apresentar a importância das UC's para a educação ambiental. Optou-se pela categoria de Parque Nacional $(\mathrm{PN})$, uma vez que existem três importantes Parques Nacionais nas regiões selecionadas, como mostra a figura 1 :

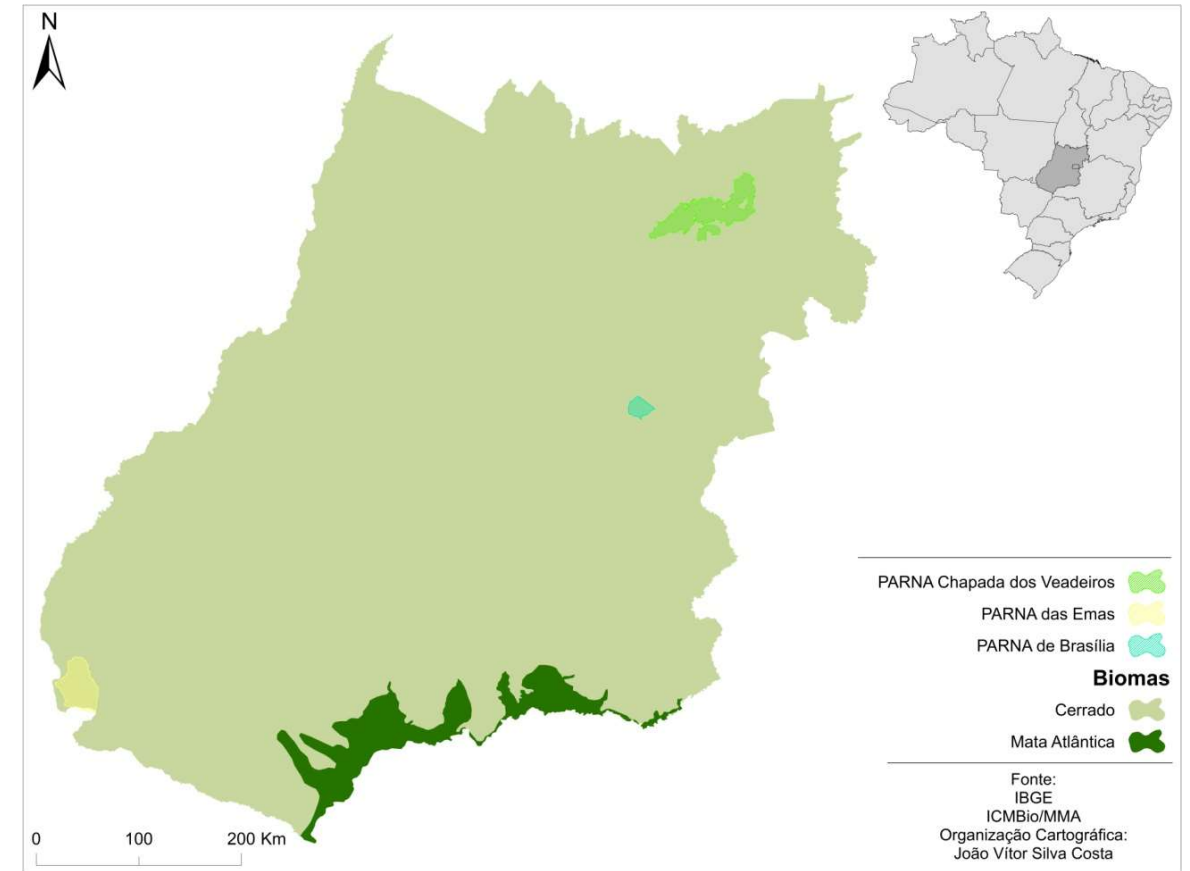

Figura 1: Localização dos parques nacionais do estado de Goiás e Distrito Federal. Fonte: IBGE, ICMBio, MMA, 2019. Organização cartográfica: João Vitor Silva Costa.

\section{METODOLOGIA}

Para concretizar os objetivos deste trabalho, elaborou-se um procedimento metodológico que foi dividido em três etapas. A primeira etapa 
contou com uma investigação bibliográfica da literatura nacional e internacional, além de teses e dissertações sobre o assunto. Na etapa seguinte fez-se um levantamento de dados vetoriais (shapefile) sobre a localização das Unidades de Conservação analisadas disponíveis gratuitamente no site do Sistema Estadual de Geoinformação do Estado de Goiás (SIEG). Em seguida foram elaborados os produtos cartográficos presentes neste trabalho. A terceira e última etapa culminou na análise das informações levantadas e na redação do texto final deste artigo.

\section{O Cerrado e suas características}

O Cerrado, de acordo com o Ministério do Meio Ambiente - MMA (BRASIL, 2019a), é o segundo maior bioma do país. Está presente em 14 dos 26 estados além do Distrito Federal. Sua área total é de mais de dois milhões de $\mathrm{km}^{2}$, ocupando cerca de $23 \%$ do território nacional (BRASIL, 2019a. Por estar localizado na região central do país e possuir ligação com praticamente todos os outros biomas (com exceção dos Pampas), é o bioma considerado com melhor posição geográfica do Brasil.

O clima do Cerrado é típico da região, o Tropical Sazonal, que é caracterizado principalmente pelas duas estações bem definidas: uma seca e uma chuvosa. Essa característica faz com que o Cerrado seja favorável tanto ao planejamento urbano quanto ao ambiental.

Por se tratar de um bioma com grande riqueza de diversidade de fauna e flora, considerado como um dos biomas mais ricos em biodiversidade do mundo (BRASIL, 2019a), o Cerrado foi classificado como um hotspot de áreas a serem conservadas no mundo. Além disso, grande parte da biodiversidade encontrada no Cerrado é considerada endêmica, ou seja, é encontrada exclusivamente no Cerrado, outra razão pela qual o bioma deve ser protegido.

As características paisagísticas do Cerrado são definidas a partir das características físicas de cada área, como substrato rochoso, declividade e presença de água. Portanto, é comum encontrar diferentes fitofisionomias em uma mesma região. Existem diferentes classificações dessas fitofisionomias, a variar de acordo com o autor que a descreve.

Como o objetivo deste trabalho não é entrar em uma discussão mais 
profunda sobre as diferentes classificações, adotou-se a classificação elaborada pelo Ministério da Agricultura, Pecuária e Abastecimento em parceria com a Embrapa, que divide o Cerrado em 14 fitofisionomias diferentes em três formações distintas, como mostra a figura 2 :

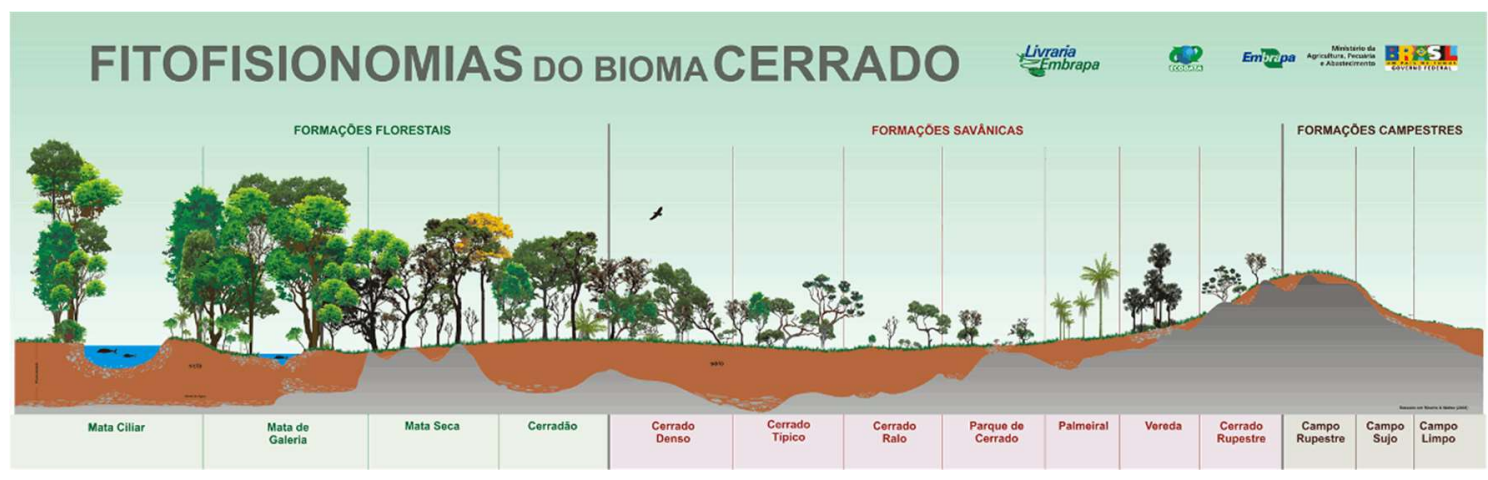

Figura 2: Fitofisionomias do Bioma Cerrado. Fonte: WWF. Disponível em: http://www.wwf.org.br/natureza_brasileira/areas_prioritarias/Cerrado/bioma/cobertura_vegetal/

Além da rica biodiversidade e do mosaico de paisagens, o Cerrado também é conhecido por ser o "berço das águas" brasileiro. Em 2012, a WWF publicou um documento chamado "Cerrado: Berço das águas", onde apresenta alguns dados sobre a disposição de água no Cerrado. De acordo com o documento:

No Cerrado nascem águas que abastecem três importantes aquíferos e seis das oito grandes bacias hidrográficas brasileiras - Amazônica, do Tocantins, Atlântico Norte-Nordeste, do São Francisco, Atlântico Leste e Paraná-Paraguai. Essa ultima esta intimamente ligada à sobrevivência do Pantanal, maior planície alagável do planeta. (WWF, 2012, p.3).

Ainda de acordo com o documento, há um grande número de brasileiros que utilizam de energia gerada nas águas do Cerrado, uma vez que o mesmo apresenta uma expressiva capacidade hídrica (WWF, 2012). Essa capacidade hídrica é fator decisivo, por exemplo, para que a região de Cristalina/GO seja a área com maior número de pivô central da América Latina.

Mesmo com tantas características que fazem do Cerrado um hotspot da conservação, o bioma enfrenta diversos problemas que ameaçam a sua existência. De acordo com Klink \& Machado (2005), as taxas de desmatamento do Cerrado têm sido historicamente superiores às da floresta amazônica. Os 
autores apontam ainda alguns problemas que o Cerrado enfrenta como a erosão de solos, a degradação dos diversos tipos de vegetação e a invasão biológica causada por gramíneas de origem africana.

A crescente expansão agropecuária também é um agravante na situação do Cerrado. Acredita-se que cerca de 2 milhões de $\mathrm{km}^{2}$ de Cerrado original tenham sido transformados em pastagem ou em culturas anuais. A relativa falta de nutrientes nos solos do Cerrado não atrapalha a expansão agrícola, uma vez que são aplicados fertilizante e calcário para que os solos se tornem produtivos para fins agrícolas (Klink \& Machado, 2005).

As diferentes ocupações do Cerrado também trazem diferentes impactos, de acordo com Klink \& Machado (2005):

As transformações ocorridas no Cerrado também trouxeram grandes danos ambientais - fragmentação de hábitats, extinção da biodiversidade, invasão de espécies exóticas, erosão dos solos, poluição de aquíferos, degradação de ecossistemas, alterações nos regimes de queimadas, desequilíbrios no ciclo do carbono e possivelmente modificações climáticas regionais. Embora o Cerrado seja um ecossistema adaptado ao fogo, as queimadas utilizadas para estimular a rebrota das pastagens e para abrir novas áreas agrícolas causam perda de nutrientes, compactação e erosão dos solos, um problema grave que atinge enormes áreas, especialmente nas regiões montanhosas do leste goiano e oeste mineiro. (Klink \& Machado, 2005, p.148).

O INPE - Instituto Nacional de Pesquisas Espaciais - apresenta gráficos de desmatamento do bioma Cerrado ao longo de anos (2001 a 2018). De acordo com os dados, Goiás é o segundo estado com o maior número de área de Cerrado desmatado, perdendo apenas para o Mato Grosso. Já o Distrito Federal se encontra em décimo lugar, como mostra a figura 3: 


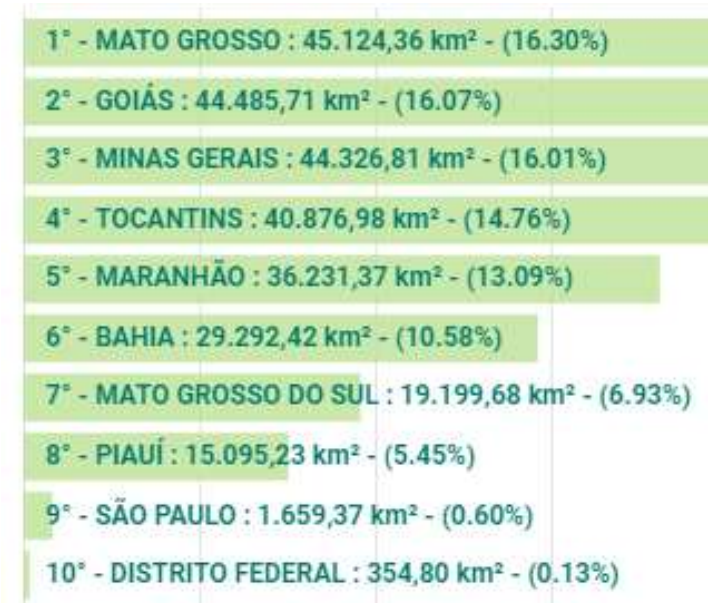

Figura 3: Incrementos de desmatamento acumulado - Cerrado. Fonte: INPE, 2019. (BRASIL, 2019b).

Ainda de acordo com o INPE, as áreas de proteção ambiental são áreas que apresentam uma área de Cerrado mais preservada, já que possuem legislações específicas que garantem que atividades predatórias não sejam praticadas em suas áreas.

Por apresentar um cenário de grande degradação no passado e ainda no presente, é importante que realizar uma análise da apropriação do Cerrado a partir das Unidades de Conservação, uma vez que, como a própria nomenclatura apresenta, o objetivo dessas áreas é a conservação e preservação.

\section{As Unidades de Conservação (UC) no Brasil, em Goiás e no Distrito Federal.}

Para que a discussão acerca da apropriação seja feita de maneira mais clara é preciso que alguns conceitos estejam bem definidos, portanto este será o ponto de partida deste item.

De acordo com o Instituto Chico Mendes - ICMBio - (BRASIL, 2019c), Unidades de Conservação (UC) são:

Espaços territoriais, incluindo seus recursos ambientais, com características naturais relevantes, que têm a função de assegurar a representatividade de amostras significativas e ecologicamente viáveis das diferentes populações, habitats e ecossistemas do território nacional e das águas jurisdicionais, preservando o patrimônio biológico existente. (BRASIL, 2019c, p.1) 
Ainda de acordo com o ICMBio, são objetivos das Unidades de Conservação também assegurar que as comunidades tradicionais tenham acesso aos recursos minerais de maneira sustentável e que a comunidade do entorno possa também desenvolver atividades econômicas sustentáveis, desde que sigam as leis e normas especificas da UC.

O ICMBio (BRASIL, 2019c), divide as UC's em dois grandes grupos: Unidades de Proteção Integral e Unidades de Uso Sustentável. As Unidades de Proteção Integral possuem normas e leis mais restritas, pois seu principal objetivo é a proteção da natureza, ou seja, preservação. Por este motivo, a utilização dos recursos naturais não pode causar danos e nem envolver coleta ou consumo. Nesta categoria estão as Estações Ecológicas (ESEC), Reservas Biológicas (REBIO), Parques Nacionais (PARNA), Monumento Natural (MN) e Refúgio de Vida Silvestre (REVIS).

Já o objetivo das Unidades de Uso Sustentável é equilibrar a conservação do ecossistema com o uso sustentável do mesmo. Por isso são permitidas atividades que pratiquem coleta e/ou consumo, desde que de modo menos agressivo e com impactos minimizados. Estão nessa categoria as Área de Proteção Ambiental (APA), Área de Relevante Interesse Ecológico (ARIE), Floresta Nacional (FLONA), Reserva Extrativista (RESEX), Reserva de Fauna (REFAU), Reserva de Desenvolvimento Sustentável (RDS) e Reserva Particular de Patrimônio Natural (RPPN). Ainda de acordo com o ICMBio (BRASIL, 2019c), no Brasil existe um sistema que agrupa todas as UC's para otimizar o planejamento e a administração das mesmas. O sistema é conhecido como SNUC - SISTEMA NACIONAL DE UNIDADES DE CONSERVAÇÃO e é gerido pelas três esferas de governo: federal, estadual e municipal.

A Lei $n^{\circ} 9.985$, de Julho de 2000 que institui o SNUC define o objetivo do Parque Nacional da seguinte forma:

O Parque Nacional tem como objetivo básico a
preservação de ecossistemas naturais de grande
relevância ecológica e beleza cênica, possibilitando a
realização de pesquisas científicas e o desenvolvimento
de atividades de educação e interpretação ambiental, de
recreação em contato com a natureza e de turismo
ecológico. (SNUC, 2000, art. 11)

Parque Nacional é a categoria de UC mais antiga no Brasil. De acordo com o ICMBio (BRASIL, 2019c), o primeiro Parque Nacional criado no país é o 
do Itatiaia, que fica localizado nos estados do Rio de Janeiro e Minas Gerais e foi criado em 1937 pelo então presidente Getúlio Vargas.

Atualmente no Brasil existem, de acordo com o ICMBio (BRASIL, 2019c), 71 Parques Nacionais. Cada qual possui um documento chamado de Plano de Manejo onde, de acordo com a Lei $n^{\circ} 9.985$, deve-se estabelecer o zoneamento e normas gerais do parque considerando sempre os objetivos gerais das UCs.

De acordo com a Secretaria do Meio Ambiente e dos Recursos Hídricos do estado de Goiás (SEMARH, 2019), existem três parques nacionais e 11 estaduais no estado de Goiás. Esta última categoria não será analisada neste trabalho. Os três Parques Nacionais presentes no estado de Goiás são: Parque Nacional das Emas, Parque Nacional da Chapada dos Veadeiros e Parque Nacional de Brasília. Segundo o ICMBio (BRASIL, 2019c) o Parque Nacional das Emas é o maior em extensão, contando com 132.642,0700 hectares.

\section{Parque Nacional da Chapada dos Veadeiros}

O Parque Nacional da Chapada dos Veadeiros (PNCV) fica localizado na mesorregião Norte do estado de Goiás. Sua área de 240.611 hectares (BRASIL, 2019c) abrange os municípios de Alto Paraíso de Goiás e Cavalcante, como mostra a figura 4.

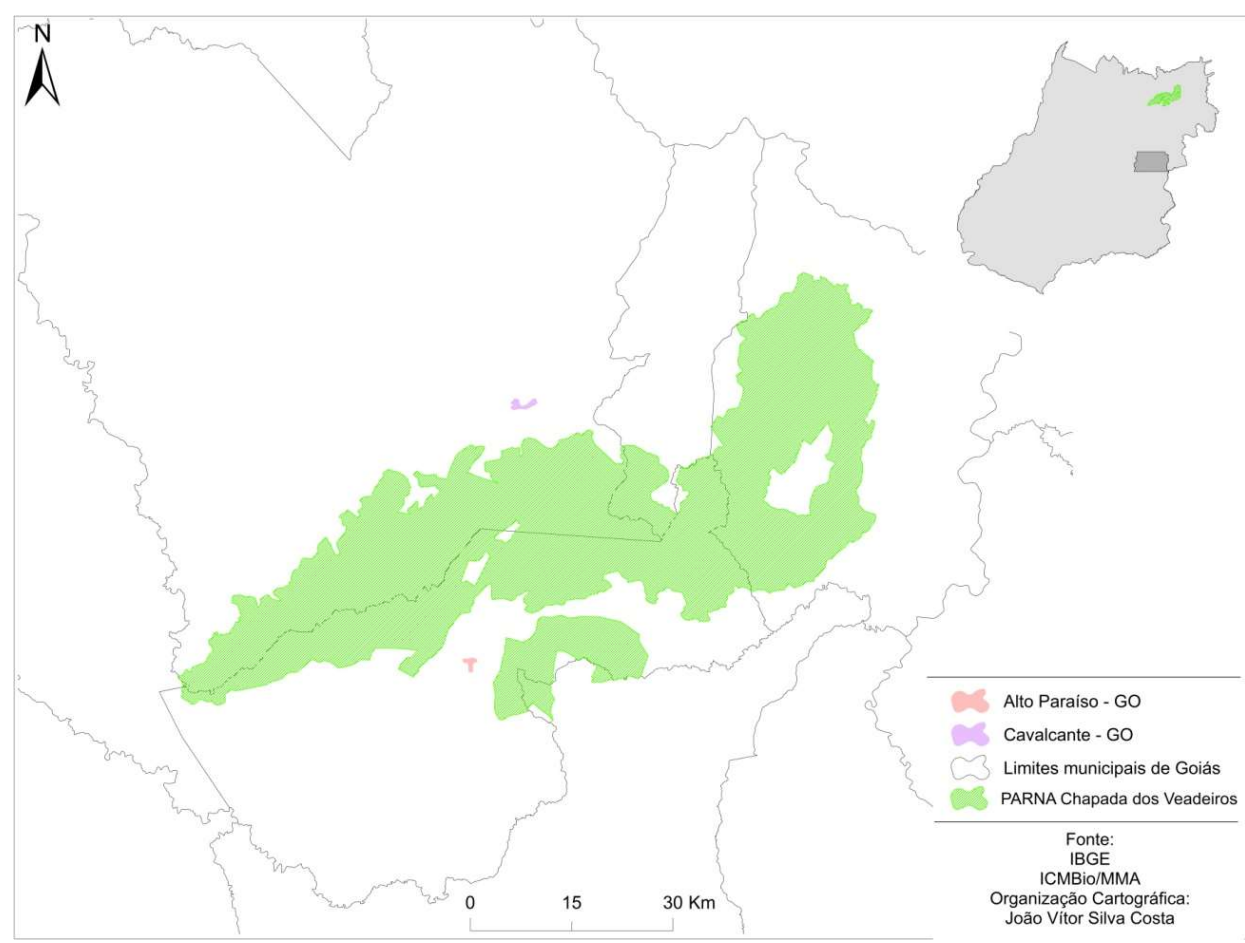

Figura 4: Mapa de Localização do Parque Nacional da Chapada dos Veadeiros. Fonte: IBGE, ICMBio -MMA, 2019. Organização Cartográfica: João Vitor Silva Costa. 
Seu acesso é dado através de duas rodovias que o margeiam, a GO118 e a GO-239. A principal entrada do parque está localizada no distrito de São Jorge, distante aproximadamente $30 \mathrm{~km}$ de Alto Paraíso de Goiás.

Primeiramente, o Parque Nacional da Chapada dos Veadeiros recebeu o nome de Parque Nacional do Tocantins e posteriormente teve seu nome e sua área alterada, e assim permaneceu até 2017, quando teve novamente sua área alterada. Entretanto, como o novo plano de manejo ainda não foi publicado, optou-se por trabalhar com a descrição da área anterior, uma vez que tal área já dispunha de plano de manejo disponível.

O Parque, de acordo com seu plano de manejo, teve sua proposta de criação feita pela Fundação Coimbra Bueno, em 1960, ao então Presidente Juscelino Kubitschek. Entretanto, o Parque passou por alterações em relação à sua área e somente em 1981 com o Decreto n 86.598 de 17 de novembro é que se delimitou em definitivo sua área (BRASIL, 2009).

A região do Parque Nacional da Chapada dos Veadeiros é conhecida nacionalmente por suas belezas cênicas e por seus atrativos como cachoeiras, que são responsáveis pela atividade turística na região. Esta atividade movimenta a economia dos municípios que investem cada vez mais em infraestrutura, como hotéis e restaurantes.

Além do turismo, as atividades produtivas da área de influência do PNCV (BRAISL, 2009) são produção agrícola, onde predomina a pequena agricultura com base familiar e com tendências a monocultura; a produção pecuária, também caracterizada pela pequena pecuária com base familiar e com tendência de crescimento apenas do rebanho bovino; produção mineral, pois se trata de uma área com grande ocorrência mineral, principalmente de quartzo, ardósia, manganês, mica, ouro, ametista e areia. O primeiro é frequentemente comercializado por vendedores da região na forma de artesanato ou como souvenir.

Sobre as características físicas do PNCV, Dardenne \& Campos (2002) afirmam que em relação à geologia o parque está inserido na porção norte da Faixa de Dobramentos e Cavalgamentos Brasília, na Província Estrutural do Tocantins. A porção noroeste da Chapada dos Veadeiros é representada, 
predominantemente por rochas do complexo granito-gnáissico e a porção sul por metassedimentos plataformais relacionados aos Grupos Arai e Paranoá.

$\mathrm{Na}$ discussão sobre a geomorfologia, Dardenne \& Campos (2002) afirmam que o parque faz parte da superfície de aplainamento Sul-Americana, que representa a mais antiga superfície de erosão da região. Os autores afirmam também que na região do PNCV podem ser discriminados três compartimentos geomorfológicos, cuja evolução é intimamente associada ao substrato rochoso e à estruturação tectônica. Os compartimentos são denominados de Região da Planície do Vale do Rio Claro, Região das Serras e Região dos Planaltos.

A altimetria varia de 800 a $1.650 \mathrm{~m}$, ocorrendo os pontos mais elevados na Chapada dos Veadeiros, ressaltados por residuais que formam a Serra da Santana, na região do Pouso Alto, que serve como divisor das bacias dos rios Montes Claros e das Almas (DARDENNE \& CAMPOS, 2002).

A rede de drenagem é a do rio Paranã e seus afluentes, alguns apresentando leitos secos geralmente preenchidos por seixos e matacões de quartzitos trabalhados. $\mathrm{O}$ rio São Bartolomeu e o rio dos Macacos posicionamse ao pé das escarpas do Complexo

Montanhoso Veadeiros-Araí e das Chapadas do Alto Rio Maranhão, a leste da cidade de Alto Paraíso de Goiás. Os rios estão encaixados no material detrítico e, sobre o plano mais alto, observam-se marcas de lagoa seca, com decantação de argila e vegetação gramíneo-lenhosa (BRASIL, 2009).

A vegetação presente no PNCV é uma variação de diferentes fitofisionomias de Cerrado. De acordo com o Plano de Manejo do parque, as elevadas altitudes e a grande disponibilidade de água são fatores que influenciam diretamente na grande diversidade de fitofisionomias presentes na área, criando "um grande mosaico de paisagens naturais". Ainda de acordo com o Plano de Manejo, foram identificadas dez fitofisionomias diferentes no parque. São elas: Cerrado rupestre, campo rupestre, Cerrado ralo, campo sujo, campo limpo, Cerrado denso, vereda, mata de galeria, mata mesofítica e cerradão. Cada fitofisionomia carrega características especificas de geomorfologia, geologia e vegetação, além da fauna e flora. 


\section{Parque Nacional de Brasília}

O Parque Nacional de Brasília (PNB) está localizado na região noroeste do Distrito Federal, distante aproximadamente $10 \mathrm{~km}$ do centro de Brasília, como mostra a figura 5 .

Com aproximadamente $42.355,54$ hectares, o acesso ao parque se dá pela Estrada Parque Indústria e Abastecimento - Via EPIA (BRASIL, 1998).

A criação do PNB está relacionada com a criação da cidade de Brasília, como mostra o seu Plano de Manejo (1998):

A criação do Parque Nacional de Brasília está intimamente relacionada com a construção da nova Capital Federal. No início da construção de Brasília, foi firmado um convênio entre o Ministério de Agricultura e a NOVACAP - Companhia de Desenvolvimento da Nova Capital, para, entre outras tarefas, propor e criar novas reservas e postos florestais no Distrito Federal. (BRASIL, 1998)

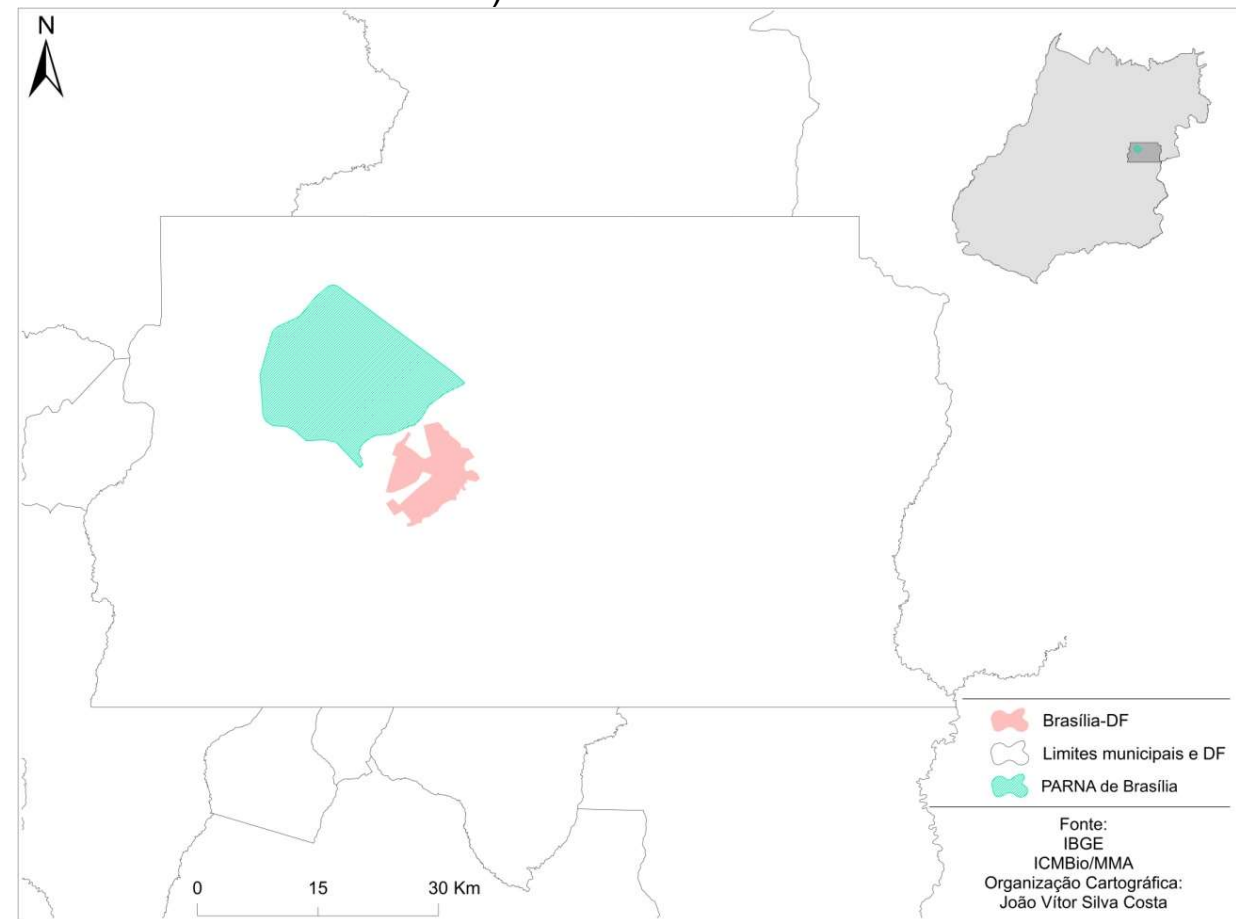

Figura 5: Mapa de Localização do Parque Nacional de Brasília. Fonte: IBGE, ICMBio -MMA, 2019. Organização Cartográfica: João Vitor Silva Costa.

O responsável pelo convênio, Dr. Hezechias Paulo Heringer, apresentou em 1960 a proposta de criação e em 29 de novembro de 1961 o então presidente Jânio Quadros assinou o decreto $n^{\circ} 241$, onde aprova a criação do Parque Nacional de Brasília. 
A principal atividade econômica praticada na área de influência do PNB (BRASIL, 1998) é a plantação de hortaliças. De acordo com a fonte, cerca de $72 \%$ da produção de hortaliças do Distrito Federal, no ano em que o plano de manejo do parque foi elaborado, era realizada na área de influência do PNB. Além disso, como está localizado em uma área muito próxima ao centro de Brasília, podem-se considerar outras que atividades como prestação de serviços e atividades industriais são praticadas também na área de influência do PNB.

Em relação às características físicas do parque, Farias et al (2008) apresentam que a geologia que o parque pertence a rochas do Grupo Paranoá de idade meso-proterozóica. De acordo com o autor, o grupo representa uma sequência deposicional limitada por duas superfícies de discordância que o separa do Grupo Araí na base e do Grupo Bambuí no topo.

Sobre a geomorfologia, BRASIL (1998) mostra que o PNB assim como o Distrito Federal está localizado no Domínio dos Planaltos em Estruturas Sedimentares Concordantes Região do Planalto Goiás Minas e Região das Chapadas do Distrito Federal.

A rede de drenagem é formada por cursos d'água de pequeno e médio porte, que fazem parte de três das principais bacias hidrográficas brasileiras: a Platina, a Amazônica e São Francisco. Os cursos d'água que drenam o PNB deságuam no rio Paranoá e são fortemente ligados a estruturação do substrato. (BRASIL, 1998).

Um dos principais recursos minerais presente no PNB é a água. As drenagens inseridas no parque são de extrema importância para a região, como mostra o Plano de Manejo (1998):

As águas de superfície e subsuperfície presentes no Parque Nacional de Brasília, por sua abundância e qualidade, são de importância estratégica para o Distrito Federal. Em termos de volume, as águas superficiais do sistema de captação das bacias dos córregos Santa Maria e Torto, contribuem atualmente com cerca de $20 \%$ do abastecimento público do DF. (BRASIL, 1998, p.29)

A vegetação típica do Cerrado presente no parque é dividida em 11 diferentes fitofisionomias, de acordo com Farias et al (2008): mata de galeria, cerradão, Cerrado strictu sensu, Cerrado ralo, Cerrado rupestre, parque de 
Cerrado, veredas, campo sujo, campo limpo, campo rupestre e campo de murundu.

\section{Parque Nacional das Emas}

O Parque Nacional das Emas (PNE) está localizado na mesorregião sudoeste do estado de Goiás. Com cerca de 132.642,0700 hectares, fica localizado entre os municípios de Mineiros e Chapadão do Céu, além de parte do município de Costa Rica, localizado no Mato Grosso do Sul (BRASIL, 2004), como mostra a figura 6 :

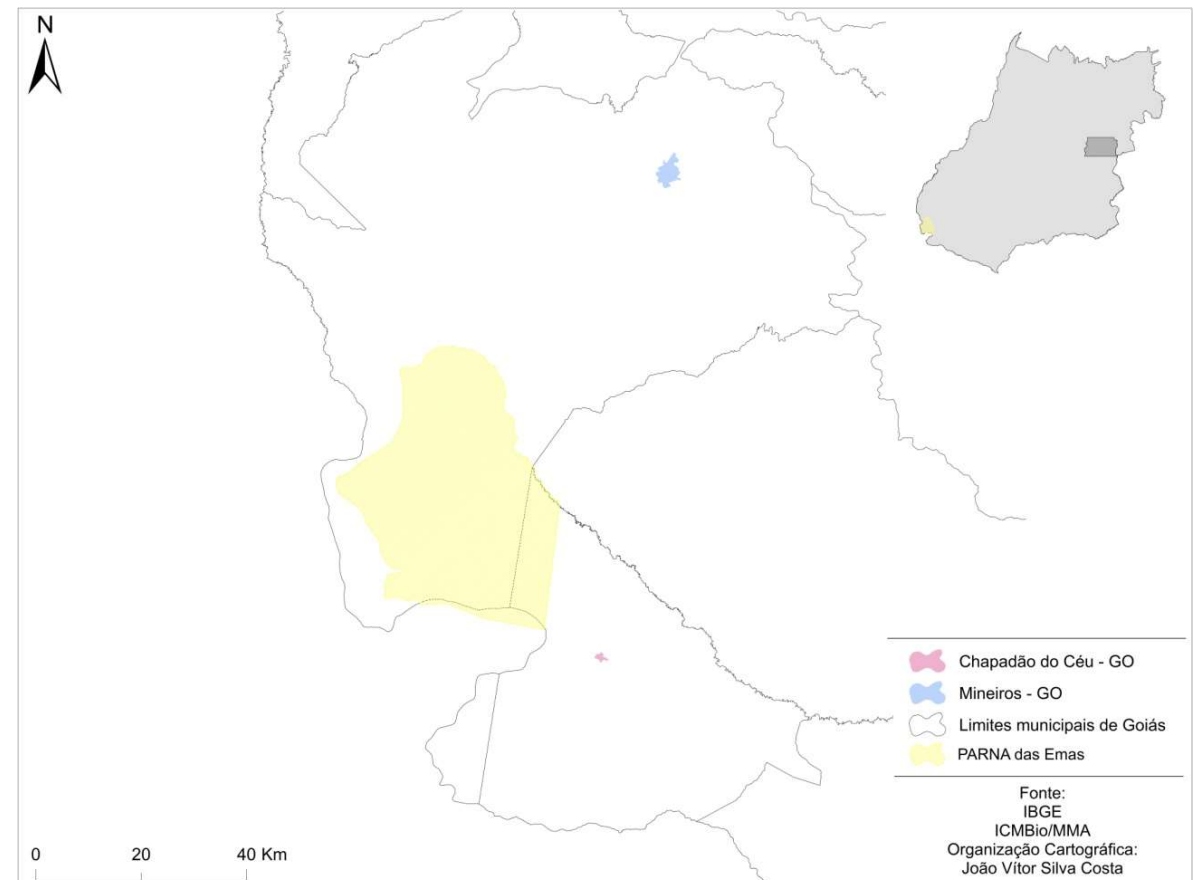

Figura 6: Mapa de Localização do Parque Nacional das Emas. Fonte: IBGE, ICMBio -MMA, 2019. Organização Cartográfica: João Vitor Silva Costa.

O acesso ao parque a partir de Brasília ou de Goiânia se dá pela BR060 até Jataí, seguindo pela GO-184 até Serranópolis e pela GO-302 até Chapadão do Céu. Outra alternativa é seguir a BR-364 até Mineiros.

De acordo com o plano de manejo do parque, o nome Parque Nacional das Emas foi escolhido devido a grande quantidade de emas presente na área. O parque está localizado na antiga Fazenda Formoso, cujo proprietário, Sr. Filogônio Garcia, é tido como precursor da criação do parque, pois apresentou sugestão quando era vereador no município de Jataí na década de 50 (BRASIL, 2004). 
Em 11 de janeiro de 1961, após o senador Coimbra Bueno apresentar a proposta, o então presidente Juscelino Kubitschek assina o decreto $n^{\circ} 49.874$ determinando a criação do Parque Nacional das Emas nos estados de Goiás e Mato Grosso (hoje Mato Grosso do Sul), compreendendo tanto terras devolutas como particulares. Em 1972, o decreto de $n^{\circ} 70.375$ foi assinado revogando o anterior e alterando a área do parque, o que resultou com que algumas importantes nascentes ficassem de fora do parque.

A principal ocupação da área de influência do PNE é a agropecuária. Moreira et al (2005) afirmam que historicamente a região é caracterizada pelo grande desenvolvimento da agropecuária, que começou em meados dos anos 70. Tal desenvolvimento levou a uma ocupação desordenada da área de influência do PNE. A atividade agropecuária é, ainda de acordo com Moreira et al (2005), uma das maiores responsáveis pelo desmatamento da região, já que através de análises pode-se perceber que grande parte da cobertura vegetal foi substituída por agricultura ou pastos.

Para Moreira et al (2005):

A atividade agrícola é a maior responsável pela abertura de novas áreas, pois, cálculos demonstram que os três municípios juntos perderam cerca de $9 \%$ de sua vegetação natural por ano, isto significa que com atual padrão de utilização do solo a região perderá sua vegetação natural, salvo as protegidas em Unidades de Conservação, nos próximos 9 anos. (MOREIRA ET AL, 2005, p.641)

É fato que existem diferentes soluções para a diminuição do desmatamento. Ações como o cumprimento correto das legislações ambientais, como o Código Florestal, e um planejamento para a ocupação da região, são algumas delas.

A respeito das características físicas do parque, o plano de manejo (BRASIL, 2004) apresenta que o contexto da geologia no parque é relativamente simples, traduzidos por uma pilha de sedimentos relativamente homogêneos e rochas vulcânicas associadas, pertencentes a Bacia Sedimentar do Paraná. Além disso, afirma que o parque é sustentado por sedimentos arenosos do Grupo Bauru, responsável pela caracterização dos solos, predominantemente arenosos. 
Sobre a geomorfologia, o PNE está localizado no Planalto Setentrional da Bacia do Paraná e compreende formas tabulares residuais nas porções elevadas, parcialmente erodidas e dissecadas ao longo dos maiores vales (BRASIL, 2004).

A altimetria pode variar entre 350 a $1000 \mathrm{~m}$, sendo que a cota mais alta (entre 650 a $1000 \mathrm{~m}$ ) representa um importante divisor de águas Paraná Paraguai - Araguaia.

Como está localizado em um grande e importante divisor de águas, o PNE faz parte tanto da bacia hidrográfica do rio Araguaia como da bacia hidrográfica do rio Paraná. Dentro dos limites do parque há nascentes de extrema importância para a rede de drenagem, como as do rio Formoso e rio Jacuba, além da nascente do próprio rio Araguaia, mencionado anteriormente. Sua rede de drenagem é composta por diversos córregos cujo padrão é ditado pela inclinação topográfica, com direção e fluxo controlados pela estrutura rochosa (BRASIL, 2004).

A vegetação é típica do Cerrado e pode-se notar uma grande variedade de fitofisionomias: campo úmido, cerradão, campo Cerrado, campo sujo, campo limpo, Cerrado strictu sensu, campo de murundus, mata ciliar e veredas (SHUVARTZ, 2006).

\section{Educação Ambiental e Unidades de Conservação}

De maneira simplista, entende-se educação ambiental (EA) como uma parte da educação voltada especificamente para o Meio Ambiente. Entretanto, Sauvé (2005) apresenta que a EA vai além de uma forma de educar voltada ao meio ambiente ou de uma ferramenta para a gestão ambiental. Para Sauvé (2005):

Trata-se de uma dimensão essencial da educação fundamental que diz respeito a uma esfera de interações que está na base do desenvolvimento pessoal e social: a da relação com o meio em que vivemos, com essa "casa de vida" compartilhada. (SAUVÉ, 2005, p. 317).

A educação ambiental é um conceito que ganhou notoriedade após os vários eventos voltados ao meio ambiente que ocorreram no mundo. Apesar de 
apresentar diferentes correntes, uma ideia é central para todos: a educação é princípio norteador do conceito. (BRASIL, 2012).

Há que compreender que a EA pode e é utilizada em diferentes setores, como mencionado na Resolução $\mathrm{N}^{\circ} 2$, de 15 de junho de 2012, que estabelece as diretrizes curriculares nacionais para a Educação Ambiental no Brasil. Nela, é possível encontrar os objetivos e os princípios em que a EA se baseia. Um dos objetivos é "desenvolver a compreensão integrada do meio ambiente em suas múltiplas e complexas relações para fomentar novas práticas sociais e de produção e consumo" (BRASIL, 2012, p.4). Nota-se que é um objetivo complexo, uma vez que se trata de mudança de costumes de produção e consumo, costumes esses impostos não somente pela família ou criação, mas pela sociedade em si. Por isso é importante entender que a EA é um conceito que deve ser trabalhado em todos os níveis da educação, mas principalmente na formação das novas gerações, ou seja, na educação básica.

Em se tratando de princípios, destaca-se um em especial: "articulação na abordagem de uma perspectiva crítica e transformadora dos desafios ambientais a serem enfrentados pelas atuais e futuras gerações, nas dimensões locais, regionais, nacionais e globais." (BRASIL, 2012, p.4). Percebe-se uma preocupação com as questões ambientais mundiais, nacionais e locais. Portanto, pode-se estabelecer uma ligação com as Unidades de Conservação, especialmente as de Proteção Integral já que apresentam como objetivo a preservação do local, utilizando-se de atividades sustentáveis, como o turismo.

E pode-se pensar em um modelo de educação ambiental nas Unidades de Conservação? Sim, pois na prática, o ICMBio é o responsável pelas atividades de EA em todo o território brasileiro que possua UC's federais. Desde sua criação, em 2007, o ICMBio promove e executa atividades voltadas a EA. (BRASIL, 2016). No caso do Cerrado é de extrema importância que a EA seja colocada em prática, uma vez que o bioma é considerado um hotspot de preservação, como já apresentado anteriormente, pois é um dos biomas mais degradados do mundo. Além disso, seu alto número de endemismo faz com que a preservação do Cerrado seja ainda mais urgente. Outra característica importante presente no Cerrado e que é fator determinante para sua proteção é a presença de comunidades tradicionais indígenas e quilombolas. Nesse 
sentido, é preciso considerar e integrar as comunidades tradicionais existentes na região, como a comunidade Kalunga e os Avá-Canoeiros. Essas comunidades contam e fazem parte da história local e precisam estar incluídas de maneira efetiva nas propostas preservacionistas e nas atividades desenvolvidas na região. Portanto, a educação ambiental teria efeito não só na proteção do meio ambiente, mas também na proteção de tais comunidades.

Atualmente, as atividades voltadas a educação ambiental praticadas nas unidades de conservação citadas são: programas de voluntariado, oficinas para visitantes e comunidade, criação de Centro de Educação Ambiental responsável por desenvolver diferentes atividades envolvendo a temática. Essas atividades são praticadas em parceria com os governos municipais, estaduais e federais e apresentam um grande envolvimento da comunidade e dos visitantes dos parques.

\section{CONSIDERAÇÕES FINAIS}

Os três parques nacionais discutidos foram criados na década de 1960.Cerrado O PNCV foi criado em 1960 enquanto o PNB e PNE foram criados em 1961.

Uma possível explicação para datas tão próximas é a expansão da agropecuária no estado de Goiás. Teixeira Neto (2008) afirma que a atividade agropecuária já estava presente no Cerrado desde quando os bandeirantes estiveram pela região. Entretanto, foi somente após a década de 40, com a revolução tecnológica e a modernização da agricultura que tal atividade começou a expandir em Goiás.

Os problemas que antes impediam a agricultura, como o $\mathrm{pH}$ ácido dos solos do Cerrado, foram rapidamente solucionados. No caso dos solos, uma correção é suficiente para corrigir tal problema.

O Parque Nacional de Brasília, como já foi apresentado, teve sua criação ligada a uma política de desenvolvimento da Capital Federal. Porém, o local foi selecionado justamente por contar com uma grande variedade paisagística ou de fitofisionomias. Ou seja, era um ótimo exemplar de espécies do Cerrado. Além disso, apresentava grande concentração de água, o que estrategicamente era muito importante para o DF. 
Foi nos anos 60 também que teve início em passos lentos o movimento a favor da sustentabilidade e da ideia de educação ambiental, que só nos anos 90 , com a Conferência da ONU para o Meio Ambiente e Desenvolvimento, a famosa Rio 92, conseguiu maior foco. Ortega (2011) afirma que foram nos anos de 60 e 70 que parte da população começou a se conscientizar sobre o uso de recursos não renováveis e sobre os impactos causados por tais usos.

O presente trabalho teve como tema a presença de UC's no Cerrado como prática da Educação Ambiental no estado de Goiás e no Distrito Federal. O trabalho contou com análise de documentos oficiais como os decretos de criação e os planos de manejo dos parques nacionais estudados. Além de bibliografias especificas sobre as fitofisionomias do Cerrado e sobre as unidades de conservação.

Destacou-se, também, a relação entre as datas de criação dos parques analisados em função da expansão agrícola e a modernização da agropecuária.

Conclui-se, por fim, que a presença de unidades de conservação no Cerrado pode e ajudam na prática da Educação Ambiental, uma vez que o mesmo órgão responsável pela gestão dos parques é responsável também pela efetiva prática da EA.

\section{REFERÊNCIAS}

BRASIL, Instituto Brasileiro do Meio Ambiente e dos Recursos Naturais (IBAMA). Plano De Manejo do Parque Nacional de Brasília. Brasília, 1998. Disponível em: http://www.icmbio.gov.br/portal/biodiversidade/unidades-de-conservacao/biomasbrasileiros/Cerrado/unidades-de-conservacao-Cerrado/2095-parna-de-brasilia

BRASIL, Instituto Brasileiro do Meio Ambiente e dos Recursos Naturais (IBAMA). Plano De Manejo do Parque Nacional das Emas. Brasília, 2004. Disponível em: http://www.icmbio.gov.br/portal/biodiversidade/unidades-de-conservacao/biomasbrasileiros/Cerrado/unidades-de-conservacao-Cerrado/2093-parna-das-emas

BRASIL, Instituto Chico Mendes (ICMBio). Plano de Manejo do Parque Nacional da Chapada dos Veadeiros. Brasília, 2009. Disponível em: http://www.icmbio.gov.br/portal/images/stories/imgs-unidadescoservacao/pm_chapada_dos_veadeiros_1.pdf

BRASIL, Lei $n^{\circ} 9.985$, de 18 de julho de 2000. Regulamenta o art. 225, § 1o, incisos I, II, III e VII da Constituição Federal, institui o Sistema Nacional de Unidades de Conservação da Natureza e dá outras providências (SNUC). Brasília-DF, 18 de julho de 2000. Disponível em: http://www.planalto.gov.br/ccivil_03/leis/l9985.htm

BRASIL, Ministério do Meio Ambiente (MMA). O Bioma Cerrado. 2019a. Disponível em: http://www.mma.gov.br/biomas/Cerrado\# 
BRASIL, Instituto Nacional de Pesquisas Ambientais (INPE). Terra Brasilis, PRODES (Desmatamento). Disponível em:

http://terrabrasilis.dpi.inpe.br/app/dashboard/deforestation/dashboard/deforestation/bio mes/cerrado/increments

BRASIL, Instituto Chico Mendes (ICMBio). Unidades de Conservação. 2019c.

Disponível em: http://www.icmbio.gov.br/cecat/conservacao-da-

biodiversidade/unidade-de-conservacao-Cerrado.html

BRASIL, Resolução $N^{\circ} 2$, de 15 de junho de 2012. Estabelece as Diretrizes Curriculares Nacionais para a Educação Ambiental.

BRASIL, Ministério do Meio Ambiente \& Instituto Chico Mendes, em parceria com a WWF-Brasil. Educação ambiental em unidades de conservação: 2016 ações voltadas para comunidades escolares no contexto da gestão pública da biodiversidade. 2016. Disponível em:

http://www.icmbio.gov.br/portal/images/stories/comunicacao/publicacoes/publicacoesdiversas/DCOM_ICMBio_educacao_ambiental_em_unidades_de_conservacao.pdf

DARDENNE, M.A \& CAMPOS, J. E. G. Parque Nacional da Chapada dos Veadeiros, GO. Sítio e grande beleza cênica do centro-oeste brasileiro. In: Schobbenhaus,C.; Campos,D.A.; Queiroz,E.T.; Winge,M.; Berbert-Born,M.L.C. (Edit.) 2002. Sítios Geológicos e Paleontológicos do Brasil. DNPM/CPRM - Comissão Brasileira de Sítios Geológicos e Paleobiológicos (SIGEP) - Brasília 2002; 554pp; ilust.

FARIAS, Marcus F. R. et al. Relação entre os solos e fitofisionomias do Parque Nacional de Brasílias, DF. Boletim de Pesquisa e Desenvolvimento/ Embrapa Cerrados. Planaltina, DF. 2008. 55p. Disponível em: http://repositorio.unb.br/bitstream/10482/16203/1/ARTIGO_RelacaoSolosFitofisionomia s.pdf

KLINK, Carlos A. \& MACHADO, Ricardo B. A conservação do Cerrado brasileiro. Revista Megadiversidade. Volume 1, n¹. p 147 - 155. 2005. Disponível em: http://www.equalisambiental.com.br/wpcontent/uploads/2013/02/Cerrado_conservacao .pdf

MOREIRA, Renato A. et al. Análise temporal do uso do solo nos municípios do entorno do Parque Nacional das Emas com a utilização de imagens Landsat e CBERS-2. Anais do XII Simpósio Brasileiro de Sensoriamento Remoto. Goiânia, GO. 2005. p. 633 - 641. Disponível em:

http://marte.sid.inpe.br/col/ltid.inpe.br/sbsr/2004/11.22.18.01/doc/633.pdf

ORTEGA, Enrique. Brasil e o desenvolvimento sustentável. Laboratório de Engenharia Ecológica, FEA, UNICAMP. 15p. Campinas, SP. 2011. Disponível em: http://www.unicamp.br/fea/ortega/Brasil/Brasil\%20e\%200\%20Desenvolvimento\%20Su stentavel.pdf

SAUVÉ, Lucie. Educação Ambiental: possibilidades e limitações. Educação e Pesquisa, São Paulo, v. 31, n. 2, p. 317-322, maio/ago. 2005.

SEMARH, Secretaria do Meio Ambiente e dos Recursos Hídricos do estado de Goiás. Disponível em: http://www.semarh.goias.gov.br/site/unidades-de-conservacao. 2019.

SHUVARTZ, Marilda. Representações sociais de biodiversidade na região do Parque Nacional das Emas - GO. Abril de 2006. Tese apresentada para defesa do 
título de Doutora. Programa de Doutorado em Ciências Ambientais. Univerisdade Federal de Goiás. Goiânia, GO. Abril de 2006. Disponível em: https://ciamb.prpg.ufg.br/up/104/o/Marilda_Shuvartz2002.pdf

TEIXEIRA NETO, Antônio. Pequena história da agropecuária goiana (o ouro acabou? Viva o boi!/ o ouro se foi? Chegou o boi!). Observatório Geográfico de Goiás. 38p. Goiânia, GO. 2008. Disponível em:

https://observatoriogeogoias.iesa.ufg.br/up/215/o/teixeira_neto_ant_nio_pequena_hist_ agropecu_ria.pdf

WWF (World Wild Fund for Nature). Cerrado: Berço das águas. 2012. Disponível em: http://d3nehc6yl9qzo4.cloudfront.net/downloads/wwf_factsheet_Cerrado_pt_web.pdf

\section{SOBRE OS AUTORES}

\section{Gabriela Couto Barbosa}

Bacharel e mestre em Geografia pela Universidade Federal de Goiás. Doutoranda do Programa de Ensino e História das Ciências da Terra Universidade Estadual de Campinas.

\section{Cláudia Valéria de Lima}

Geóloga formada pela Universidade de Brasília. Mestre em Geociências pela Universidade Estadual de Campinas. Doutora em Geologia pela Universidade de Brasília. Atualmente, professora Associada da Universidade Federal de Goiás.

\section{André Munhoz de Argollo Ferrão}

Graduado em Engenharia Civil pela Universidade Estadual de Campinas e em Arquitetura e Urbanismo pela Pontifícia Universidade Católica de Minas Gerais. Mestre em Engenharia Agrícola pela Universidade Estadual de Campinas. Doutor em Arquitetura e Urbanismo pela Universidade de São Paulo. Atualmente, professor Livre-docente da Universidade Estadual de Campinas.

\section{João Vitor Silva}

Bacharel em ciências ambientais, bolsista do laboratório de processamento de imagens e geoprocessamento (Lapig) da Universidade Federal de Goiás. 